TAVEIRA, R.Z. et al. Comparação de desempenho de bovinos Nelore e mestiços Nelore-Rubia Gallega em sistema de confinamento. PUBVET, Londrina, V. 8, N. 6, Ed. 255, Art. 1691, Março, 2014.

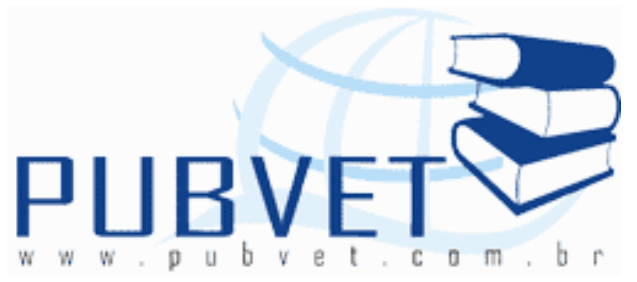

PUBVET, Publicações em Medicina Veterinária e Zootecnia.

\title{
Comparação de desempenho de bovinos Nelore e mestiços Nelore- Rubia Gallega em sistema de confinamento
}

\section{Rodrigo Zaiden Taveira ${ }^{1}$, Osvaldo José da Silveira Neto ${ }^{1}$, Allinydas Graças} Amaral $^{1}$, Thais Nunes Luz ${ }^{2}$, Vanderly Alves de Brito Júnior ${ }^{2}$

${ }^{1}$ Docente e Pesquisador - Curso de Zootecnia - UEG - UnU - São Luís de Montes Belos, GO

${ }^{2}$ Acadêmicos do curso de Zootecnia - UEG - UnU - São Luís de Montes Belos, GO

\section{Resumo}

A utilização de confinamentos para a terminação de bovinos de corte vem crescendo no Brasil, juntamente com a adoção de cruzamentos para aumentar a eficiência produtiva dos animais nesse sistema intensivo. Objetivou-se comparar o ganho em peso médio diário, o rendimento de carcaça, a conversão alimentar e a eficiência biológica de novilhos da raça Nelore e de mestiços Nelore-Rubia Gallega mantidos em confinamento. Foram utilizados 276 bovinos inteiros, sendo 140 da raça Nelore e 136 mestiços com idade variando entre 21 e 24 meses de idade. Os animais foram separados em baias coletivas de acordo com o grupo genético, permanecendo 87 dias no confinamento. As dietas fornecidas eram de alto concentrado, com exceção da dieta de adaptação. As análises estatísticas foram realizadas pelo programa estatístico SAS,e as médias do peso inicial, ganho médio diário e peso final 
TAVEIRA, R.Z. et al. Comparação de desempenho de bovinos Nelore e mestiços Nelore-Rubia Gallega em sistema de confinamento. PUBVET, Londrina, V. 8, N. 6, Ed. 255, Art. 1691, Março, 2014.

foram comparadas pelo teste $t(p<0,01)$. O rendimento de carcaça foi determinado em relação ao peso de corpo vazio da carcaça quente e o peso vivo de saída. A conversão alimentar foi calculada através dos $\mathrm{Kg}$ de MS consumidos $/ \mathrm{Kg}$ de ganho. A eficiência biológica foi medida tendo em vista a quantidade de $\mathrm{Kg}$ de MS consumida/arroba de carcaça produzida.O ganho médio diário, peso final médio e rendimento de carcaça dos animais mestiços Nelore-Rúbia Gallega foram superiores em relação aos animais da raça Nelore $(p<0,01)$. Quanto a conversão alimentar os mestiços consumiram 1,39 $\mathrm{Kg}$ de MS a menos para cada $\mathrm{Kg}$ de ganho em peso. Em relação a eficiência biológica para cada arroba produzida os animais Nelores tiveram que consumir $37,09 \mathrm{Kg}$ de MS a mais do que os mestiços Nelore-Rubia Gallega. A utilização de animais com genética Rubia Gallega em cruzamentos com animais da raça Nelore proporcionou melhoria nos parâmetros avaliados.

Palavras-chave: conversão alimentar; cruzamento industrial; rendimento de carcaça.

\title{
Performance comparation between Nellore and crossbreed Nellore- Rubia Galega in feedlot system
}

\begin{abstract}
The use of feedlots to carcass termination in beef cattle have been increase in the Brazil, in addition with de crossbreed systems aiming increase the productive efficiency of animals in this system. The aim of this study was to compare the daily average weight gain performance, carcass yield, alimentary conversion and the biological efficiency of Nellore steers and the crossbreed Nelore-RubiaGallega kept in feedlot. It was used 276 bovines, being 140 of Nellore breed and 136 crossbreed with age ranging from 21 to 24 months. The animals were divided in collective installations according to the genetic group, kept 87 days in the feedlot. The diet used had high concentrated, exception the diet of the adaptation period. The statistical analysis were carried out by SAS - Statistical Analysis System and the average of initial weight, daily
\end{abstract}


TAVEIRA, R.Z. et al. Comparação de desempenho de bovinos Nelore e mestiços Nelore-Rubia Gallega em sistema de confinamento. PUBVET, Londrina, V. 8, N. 6, Ed. 255, Art. 1691, Março, 2014.

average gain and final weight were compared by the test $(p<0.01)$. The carcass yield was determined by the relationship between the weight of the empty body of the hot carcass by the final weight. The alimentary conversion was calculated by $\mathrm{Kg}$ of dry matter intake divided by the $\mathrm{kg}$ of gain. The biological efficiency was measured by $\mathrm{kg}$ of dry matter intake divided by the arrobas of carcass produced. The daily average gain, average final weight and carcass yield of Nellore-RubiaGallega animals were superior than the Nellore ones $(p<0.01)$. Considering the alimentary conversion, the crossbred animals did intake $1.39 \mathrm{~kg}$ of dry matter less for each $\mathrm{kg}$ of weight gain. Considering the biological efficiency, for each arroba produced the Nellore animals had been consumed $37.09 \mathrm{~kg}$ of dry matter more than the crossbreed ones. The utilization of animals with Rubia-Gallega genetic in crossbreed systems with Nellore show improvement in the parameters evaluated.

Keywords: alimentary conversion; industrial crossbreed; carcass yield.

\section{Introdução}

A terminação de bovinos de corte em confinamento é uma prática que vem crescendo no Brasil, permitindo maior flexibilidade no manejo dos animais, por meio do fornecimento de alimentação adequada nos períodos em que a disponibilidade de forragem é reduzida (ABRAHÃO, 2006).

De acordo com CARRIJO (2010), o confinamento deve ser encarado como uma alternativa estratégica para produzir animais precoces, com bom acabamento de carcaça e que atendam as necessidades das indústrias de processamento da carne.

Assim é cada vez maior o interesse dos pecuaristas por tecnologias que concorram para aumentar a eficiência produtiva dos animais confinados (MOURA, 2012). Nesse contexto, tem-se procurado, por meio do cruzamento, combinar e complementar as características de importância econômica que são 
TAVEIRA, R.Z. et al. Comparação de desempenho de bovinos Nelore e mestiços Nelore-Rubia Gallega em sistema de confinamento. PUBVET, Londrina, V. 8, N. 6, Ed. 255, Art. 1691, Março, 2014.

expressas com diferente intensidade pelos animais das raças puras (RESTLE et al., 2000).

Conforme BURROW et al. (2001), isso ocorre pela completa expressão da heterose, a qual é medida pela diferença entre o desempenho médio dos mestiços (F1) e a média das raças parentais.

Entre os benefícios que os cruzamentos proporcionam à pecuária bovina de corte, o aumento do peso e a melhoria da qualidade das carcaças estão entre os que podem ser alcançados imediatamente (RODRIGUES et al., 2008). Assim, o cruzamento Rubia Gallega e Nelore no Brasil, representa uma categoria animal de desempenho superior contribuindo para melhores índices produtivos. Além de atender as preferências dos consumidores por carne de melhor qualidade.

Assim, segundo RESENDE et al. (2009), os parâmetros normalmente utilizados na avaliação do desempenho dos animais terminados em confinamento são: o ganho em peso médio diário dos animais, a conversão alimentar bem como o rendimento de carcaça.

O presente estudo teve como objetivo comparar o desempenho de novilhos Nelore e mestiços Nelore-Rubia Gallega em sistema de confinamento, tendo em vista o ganho em peso médio diário, o rendimento de carcaça, a conversão alimentar e a eficiência biológica.

\section{Material e métodos}

O experimento foi conduzido em propriedade localizada no município de Pontal do Araguaia, estado do Mato Grosso. Foram utilizados 273 bovinos inteiros, sendo 140 da raça Nelore e 136 mestiços Nelore-Rubia Galega com idade variando de 21 a 24 meses. Foi utilizado um delineamento inteiramente casualizado com dois tratamentos $(T 1=$ Nelore e $T 2=$ Nelore-Rubia-Galega) e quatro repetições por tratamento. No caso do $T 1$, cada repetição possuía 35 amimais enquanto que cada repetição do T2 contou com 34 animais. Os 
TAVEIRA, R.Z. et al. Comparação de desempenho de bovinos Nelore e mestiços Nelore-Rubia Gallega em sistema de confinamento. PUBVET, Londrina, V. 8, N. 6, Ed. 255, Art. 1691, Março, 2014.

animais pertenciam à mesma propriedade e foram submetidos aos mesmos manejos, incluindo controle de endo e ectoparasitas.

Os animais foram distribuídos em 08 currais, sendo 04 para cada tratamento, respeitando-se área de $12,7 \mathrm{~m}^{2}$ por animal. A instalação do confinamento tinha piso compactado de terra, área próxima aos bebedores em concreto e divisórias de arame liso. Os bebedouros coletivos localizavam-se na divisória de duas baias e o comedouro de concretos, dispostos paralelamente aos corredores de manejo, com $37 \mathrm{~cm}$ lineares para cada animal.

Os pesos foram aferidos utilizando-se balança eletrônica própria para pesagem de bovinos, sendo o peso inicial e final aferido na própria fazenda após jejum alimentar de 16 horas.

O período experimental teve duração de 86 dias, entre os meses de maio e agosto de 2012. Foram utilizadas uma dieta de adaptação durante 11 dias e quatro dietas de terminação (01, 02, 03 e 04), durante 08, 16, 18 e 33 dias, respectivamente.

Com exceção da dieta de adaptação, todas as outras dietas fornecidas eram de alto concentrado. A relação volumoso: concentrado das dietas eram: Adaptação (43,83:56,17); Terminação01 (27,53:72,47); Terminação02 $(13,51: 86,49)$; Terminação03 $(11,57: 88,43)$ e Terminação04 $(10,09: 89,91)$.

A composição percentual da dieta fornecida aos animais (\% na MS) encontra-se apresentada na Tabela 1.

As dietas total foram balanceadas, para ganho em peso vivo diário de 1,8 $\mathrm{kg}$, utilizando-se o Programa SuperCrac bovinos de corte 4.1 para ajuste da mesma.

As determinações de matéria seca (MS), proteína bruta (PB) e nutrientes digestíveis totais (NDT) foram obtidos por meio do programa de formulação dessas dietas. Na Tabela 2 encontram-se os teores médios de MS, PB e NDT das dietas fornecida aos animais. 
TAVEIRA, R.Z. et al. Comparação de desempenho de bovinos Nelore e mestiços Nelore-Rubia Gallega em sistema de confinamento. PUBVET, Londrina, V. 8, N. 6, Ed. 255, Art. 1691, Março, 2014.

Tabela1. Composição percentual da dieta (Adaptação; Terminação - 01; Terminação - 02; Terminação - 03 e Terminação - 04) fornecida aos animais Nelore e mestiços Nelore-Rubia Galega ao longo de 86 dias de confinamento realizado em propriedade localizada no município de Pontal do Araguaia, MT, entre os meses de maio e agosto de 2012.

\begin{tabular}{lccccc}
\hline & \multicolumn{5}{c}{ MS (\%) } \\
\hline Ingredientes & & \multicolumn{4}{c}{ Terminação } \\
\cline { 3 - 6 } & Adaptação & 01 & 02 & 03 & 04 \\
\hline Silagem de Sorgo & 41,84 & 25,58 & 12,52 & 10,39 & 8,77 \\
Caroço de Algodão & 7,27 & 11,67 & 15,89 & 16,54 & 15,78 \\
Casca de Soja & 7,95 & 7,90 & 8,18 & 7,78 & 6,58 \\
Sorgo Grão & 36,77 & 48,63 & 58,11 & 60,00 & 63,83 \\
Suplemento Mineral com & 3,29 & 3,40 & 3,48 & 3,31 & 3,33 \\
Uréia * & 0,89 & 0,88 & 0,83 & 0,79 & 0,39 \\
Uréia & & & & & \\
Bagaço de Cana-de- & 1,99 & 1,95 & 0,99 & 1,18 & 1,32 \\
açúcar & & & & & \\
\hline
\end{tabular}

*Níveis de garantia por $\mathrm{Kg}$ de produto: cálcio máx (315g), cálcio mín (285g), cobalto $(50 \mathrm{mg})$, cobre $(375 \mathrm{mg})$, cromo $(2,8 \mathrm{mg})$, enxofre $(18,9 \mathrm{~g})$, ferro (209mg), flúor Max (250mg), fósforo (25g), iodo (24mg), magnésio $(15,95 \mathrm{~g})$, manganês (208mg), NNP equivalente em proteína máx $(425 \mathrm{~g})$, potássio $(50 \mathrm{~g})$, selênio $(3,6 \mathrm{mg})$, sódio $(16 \mathrm{mg})$, vitamina A (85000UI), vitamina E (150UI), zinco $(1016 \mathrm{mg})$, vitamina PP $(1250 \mathrm{mg})$, monensina sódica $(600 \mathrm{mg})$, B. H. T. (300mg). 
TAVEIRA, R.Z. et al. Comparação de desempenho de bovinos Nelore e mestiços Nelore-Rubia Gallega em sistema de confinamento. PUBVET, Londrina, V. 8, N. 6, Ed. 255, Art. 1691, Março, 2014.

Tabela 2. Teores médios de matéria seca (MS), proteína bruta (PB), nutrientes digestíveis totais (NDT) das dietas fornecidas aos bovinos da raça Nelore e mestiços Nelore-Rúbia Gallega ao longo de 86 dias de confinamento realizado em propriedade localizada no município de Pontal do Araguaia, MT, entre os meses de maio e agosto de 2012.

\begin{tabular}{lccc}
\hline Dietas & MS (\%)* & \multicolumn{2}{c}{ Teores de nutrientes na matéria seca } \\
\cline { 3 - 4 } & & PB (\%)* & NDT (\%)* \\
\hline Adaptação & 58,65 & 12,55 & 69,14 \\
Terminação 01 & 67,69 & 13,79 & 70,87 \\
Terminação 02 & 76,52 & 14,37 & 76,87 \\
Terminação 03 & 74,09 & 14,34 & 77,44 \\
Terminação 04 & 75,53 & 13,76 & 76,90 \\
\hline
\end{tabular}

*Valores obtidos pelo programa de formulação de dietas SuperCrac bovinos de corte 4.1 .

As variáveis de desempenho avaliadas foram: ganho em peso médio diário (GMD), rendimento de carcaça (RC), conversão alimentar (CA) e eficiência biológica (EB). As análises estatísticas foram realizadas pelo programa estatístico SAS(SAS, 2006)e as médias do peso inicial (PI), GMD e peso final (PF) comparadas pelo teste $t(p<0,01)$.

Os rendimentos da carcaça foram determinados em relação ao peso de corpo vazio da carcaça quente fornecido pelo frigorífico comercial e o peso vivo de saída colhido na propriedade após 16 horas de jejum.

O cálculo da conversão alimentar foi realizado tendo em vista os $\mathrm{Kg}$ de MS consumidos pelo $\mathrm{Kg}$ de ganho. A eficiência biológica foi medida considerando os quilos de matéria seca consumidos pela arroba de carcaça produzida. 
TAVEIRA, R.Z. et al. Comparação de desempenho de bovinos Nelore e mestiços Nelore-Rubia Gallega em sistema de confinamento. PUBVET, Londrina, V. 8, N. 6, Ed. 255, Art. 1691, Março, 2014.

\section{Resultados e discussão}

A tabela 3 dada abaixo apresenta os valores mínimos, médios, desviospadrões (DP) e máximos do peso inicial (PI), ganho em peso médio diário (GMD), peso final (PF) e rendimento de carcaça (RC) dos animais participantes do experimento.

Tabela 3. Valores mínimos, médios, desvios-padrões (DP) e máximos do peso inicial (PI), ganho em peso médio diário (GMD), peso final (PF) e rendimento de carcaça (RC) de bovinos da raça Nelore e mestiços Nelore-Rúbia Galega mantidos em confinamento realizado em propriedade localizada no município de Pontal do Araguaia, MT, entre os meses de maio e agosto de 2012.

\section{Nelore}

Mínimo

Média \pm DP Máximo Mínimo

Nelore-Rúbia Gallega

\begin{tabular}{ccccccc} 
& Mínimo & Média \pm DP & Máximo & Mínimo & Média \pm DP & Máximo \\
\hline PI (Kg) & 323 & $327,53 \pm 16,01_{\mathrm{ns}}$ & 396 & 328 & $317,28 \pm 44,20_{\mathrm{ns}}$ & 446 \\
$\mathrm{GMD}(\mathrm{Kg})$ & 0,82 & $1,30 \pm 0,28 *$ & 2,57 & 0,72 & $1,69 \pm 0,23 *$ & 1,91 \\
PF (Kg) & 433 & $439,72 \pm 28,70^{*}$ & 572 & 304 & $463,12 \pm 52,63^{*}$ & 582 \\
RC (\%) & 50,10 & $53,96 *$ & 54,15 & 53,10 & $55,18^{*}$ & 56,17 \\
\hline
\end{tabular}

* significativo pelo teste $t(p<0,01)$.

Como pode ser observado nos resultados dispostos na tabela 3, houve diferença significativa $(p<0,01)$ no ganho em peso médio diário entre os animais da raça Nelore e os mestiços Nelore-Rubia Galega, apresentando valores de 1,30 e 1,69 kg/dia, respectivamente. Também pode ser constatado que houve diferença significativa $(p<0,01)$ entre o peso final médio dos dois 
TAVEIRA, R.Z. et al. Comparação de desempenho de bovinos Nelore e mestiços Nelore-Rubia Gallega em sistema de confinamento. PUBVET, Londrina, V. 8, N. 6, Ed. 255, Art. 1691, Março, 2014.

grupos avaliados, sendo de 439,72 e $463,12 \mathrm{Kg}$ para os animais da raça Nelore e mestiços Nelore-Rubia Galega, respectivamente.

Os resultados obtidos nesse estudo indicaram superioridade no ganho em peso médio diário e peso final médio dos animais mestiços em detrimento aos da raça Nelore, corroborando com os resultados encontrados por LEMA (2001) o qual tambémevidenciou superioridade de desempenho de zebuínos mestiçados com raça taurina em relação à raça Nelore pura.

Resultado este também foi encontrados por BIANCHINI et al. (2008), os quais avaliaram o desempenho de quatro grupos genéticos de bovinos confinados em sistema de produção superprecoce, identificando superioridade dos mestiços zebuínos-taurinos em relação aos animais da raça Nelore.

Tendo em vista os resultadosdo rendimento de carcaça apresentados na tabela 3, pode ser constatado que os animais mestiços Rubia-Gallega apresentaram rendimento $1,22 \%$ superior aos de raça Nelore, ressaltando superioridade das raças taurinas continentais para a produção de carne.O rendimento de carcaça é um parâmetro muito importante para a viabilidade do confinamento, já que os frigoríficos comerciais comercializam a produção por meio do peso da carcaça quente.

Os resultados de rendimento de carcaça encontrados nesse estudo corroboram com os obtidos por SÁNCHEZ et al. (2005), que ao avaliarem o cruzamento de mestiços inteiros Nelore-Rubia Gallega com animais puros Nelore de mesma idade e submetidos aos mesmos manejos desde o seu nascimento e terminados em sistema de confinamento, observaram aumento de 3,46\% no rendimento de carcaça dos mestiços em relação aos puros.

Acrescenta-se ainda que os 55,18 \% de RC encontrado nesse estudo para os animais mestiços foi superior aos resultados encontrados por PEROTTO et al. (2000), que verificaram rendimentos de carcaça de animais de diversos cruzamentos situando-se entre 53,1 e 54,5\%.

Como pode ser observado nos resultados encontrados na tabela 4 , os mestiços apresentaram conversão alimentar e eficiência biológica melhor do 
TAVEIRA, R.Z. et al. Comparação de desempenho de bovinos Nelore e mestiços Nelore-Rubia Gallega em sistema de confinamento. PUBVET, Londrina, V. 8, N. 6, Ed. 255, Art. 1691, Março, 2014.

que os Nelores puros. Para cada $01 \mathrm{Kg}$ de ganho em peso os mestiços consumiram 1,39 $\mathrm{Kg}$ de MS a menos que os animais da raça Nelore.

Tabela 4. Valores médios de conversão alimentar (CA) e eficiência biológica (EB) de bovinos da raça Nelore e mestiços Nelore-Rúbia Gallega submetidos ao confinamento da fazenda Ferradura no ano de 2012.

\begin{tabular}{lcc}
\hline & Nelore & $\begin{array}{c}\text { Mestiços Nelore-Rubia } \\
\text { Gallega }\end{array}$ \\
\hline CA (Kg MS/kg de ganho em peso) & 7,0 & 5,61 \\
EB (Kg MS/arroba produzida) & 161,130 & 124,04 \\
\hline
\end{tabular}

A conversão alimentar observada nos animais mestiços Nelore-Rubia Gallega foi superior em relação aos da raça Nelore. Resultados este também foram obtidos por GALVÃO et al. (1991), os quais observaram melhor conversão alimentar para mestiços $1 / 2$ europeus-zebus em dietas que possibilitaram altas taxas em ganho em peso.

Destaca-se ainda que a conversão alimentar dos dois grupos genéticos avaliadosnesse estudo (Nelore e Nelore-Rúbia Gallega) foram superiores aos resultados obtidos encontrados por RESTLE et al. (2004), que confinando 50 novilhos Charolês, Nelore e suas cruzas, dos 19 aos 23 meses, obtiveram média de CA de 7,5 .

Considerando os resultados do presente estudo, pode ser percebido que para cada 01 arroba produzida os animais da raça Nelore tiveram que consumir 37,09 $\mathrm{Kg}$ de MS a mais do que os mestiços Nelore-Rubia Gallega, ou seja, para cada $01 \mathrm{Kg}$ produzido, os Nelores tiveram que consumir $2,48 \mathrm{Kg}$ de MS a mais do que os mestiços.

A eficiência biológica foi utilizada para reforçar o parâmetro de conversão alimentar, demonstrando a superioridade em produção de carne dos mestiços 
TAVEIRA, R.Z. et al. Comparação de desempenho de bovinos Nelore e mestiços Nelore-Rubia Gallega em sistema de confinamento. PUBVET, Londrina, V. 8, N. 6, Ed. 255, Art. 1691, Março, 2014.

analisados. Acrescenta-se que o frigorífico comercial onde estes animais foram abatidos comercializa a produção por meio do peso da carcaça quente.

\section{Conclusão}

Tendo-se em vista a utilização em confinamento de bovinos que apresentem melhor desempenho produtivo, medido pelo rendimento de carcaça, conversão alimentar e eficiência biológica, sugere-se a utilização de animais com genética Rubia-Gallega em cruzamentos com animais de raça Nelore.

\section{Referências bibliográficas}

ABRAHÃO, J. J. S.; PRADO, I. N.; MARQUES, J. A.; PEROTTO, D.; LUGÃO, S. M. B. Avaliação da substituição do milho pelo resíduo seco da extração da fécula de mandioca sobre o desempenho de novilhas mestiças em confinamento. Revista Brasileira de Zootecnia, Viçosa, v.35, n.2, p.512-518, 2006.

BIANCHINI, W.; SILVEIRA, A. C.; ARRIGONI, M. B; Crescimento e características de carcaça de bovinos superprecoces Nelore, Simental e mestiços. Revista Brasileira de Saúde e Produção Animal, Ondina, v.9, n.3, p.554-564, 2008.

BURROW, H. M.; MOORE, S. S.; JOHNSTON, D. J.; BARENDESE, W.; BINDON, B. M. Quantitative and molecular genetic influences on properties of beef:a review.

AustralianJournalof Experimental Agriculture, n.41. p.893-919, 2001.

CARRIJO, L. H. D.Viabilidade de montagem de um confinamento para terminação de bovinos de corte. 2010. 35f. Monografia (Especialista em Gestão Estratégica do Agronegócio)-Gestão Estratégica do Agronegócio Management, Goiânia. 2010.

GALVÃO, J. G.; FONTES, C. C. A.; PIRES, C. C.; QUEIRÓZ, A. C. Ganho de peso, consumo e conversão alimentarem bovinos não castrados, de três grupos raciais, abatidos em diferentes estágios de maturidade (estudo I). Revista Brasileira de Zootecnia, Viçosa, v.20, p.494-501, 1991.

LEMA, A. C. F. Produção e qualidade de carcaças de bovinos terminados em confinamento. 2001. 95f. Tese (Doutorado em Zootecnia) - Faculdades de Ciências Agrárias e Veterinária, Universidade de São Paulo, Jaboticabal. 2001.

MOURA, E.Confinamento de boi no país pode crescer 13\% em 2012 ante 2011, diz Assocon. On-line. Disponível em:<http://pecuaria.ruralbr.com.br/noticia/2012/05/confinamento-de-boino-pais-pode-crescer-13-em-2012-ante-2011-diz-assocon-3765450.html>. Acesso em: 30 de outubro de 2012. 
PEROTTO, D.; ABRAHÃO, J. J. S.; MOLETTA, J. L. Características quantitativas de carcaça de bovinos Zebu e de cruzamentos BosTaurus x Zebu. Revista Brasileira de Zootecnia, v.29, n.6, p.20119-2029, 2000.

RESENDE, P. L. P. MOREIRA, P. C.; WASCHECK, R. C., FREITAS NETO, M. D.;ALVES, V. A. Níveis de concentrado na terminação de bovinos. Estudos, Goiânia, v.36, n.11, p.1241-1262, novembro de 2009.

RESTLE, J.; ALVES FILHO, D. C.; FATURI, C. et al. Desempenho na fase de crescimento de machos bovinos inteiros ou castrados de diferentes grupos genéticos. Revista Brasileira de Zootecnia, Viçosa, v.29, n.4, p.1036-1043, 2000.

RESTLE, J.; FATURI, C.; ALVES FILHO, D. C.; BRONDANI, I. L. ;SILVA, J. H. S.; KUSS, F.; SANTOS, C. V. M.; FERREIRA, J. J.Substituição do Grão de Sorgo por Casca de Soja na Dieta de Novilhos Terminados em Confinamento. Revista Brasileira de Zootecnia, Viçosa, v.33, n.4, p.1009-1015, 2004.

RODRIGUES, K.K.N.L.; ROSSI JUNIOR, P.; MOLETTA, J.L.Avaliação das características de carcaça de bovinos mestiços Purunã, alimentados com diferentes níveis de energia na dieta.ArchivesofVeterinary Science, v.13, n.4, p.265-273, 2008.

SÁNCHEZ, L.; CARBALLO, J. A.; SÁNCHEZ, B.; MONSERRAT, L. Características de la canal y de la carne de machos procedentes delcruce de Rubia Gallegacon Nelore. Archivos de Zootecnia, v.54, p. 485-489, 2005.

SAS Institute. SAS Technical Report. SAS/STAT software: Changes and Enhancement, Release 9.1. 3, Cary NC: SAS Institute. 2006 